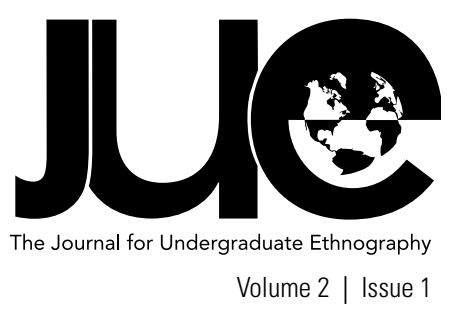

\title{
Exchanging Culture?: Opportunities for Intercultural Interaction at the Halifax International Market
}

\author{
Alison Froese-Stoddard
}

Dalhousie University, afs@dal.ca

\section{ABSTRACT}

$\mathrm{n}$ this paper, I explore the 'International Market', a unique initiative designed by the management of the Halifax Seaport Farmers Market, and Immigrant Settlement and Integration Services in Halifax, Nova Scotia. The public space of the market provides the opportunity to study the interactions between cosmopolitan consumers and immigrant vendors, while examining the larger question of immigrant integration into the community of a mid-sized Canadian city as well. Semi-structured interviews were conducted with the market management, the business development team at ISIS, and with vendors and consumers participating in the International Market to ascertain the social and/or economic benefits to each participant. The research reveals the opportunities for, and limits to intercultural exchange between newcomers and long-term citizens in a public market space.

Keywords: immigrant integration, farmers market, public space, cosmopolitan, community 
The official opening of the Halifax

Seaport International Market was

Friday, November 19, from 12:00 - 2:00

$\mathrm{pm}$. Vendors sold authentic foods, fair

trade products and crafts from around the

world. The official opening was marked

by a visit from Minister of Immigration

Ramona Jennex, who spoke about the

importance of immigrant business to the

future of Halifax, and sampled some

of the international cuisine.

Be sure to check it out, as every Friday is

International Market day! Admission is free and everyone is welcome.

- Taken from ISIS (Immigration Settlement and Integration Services) website

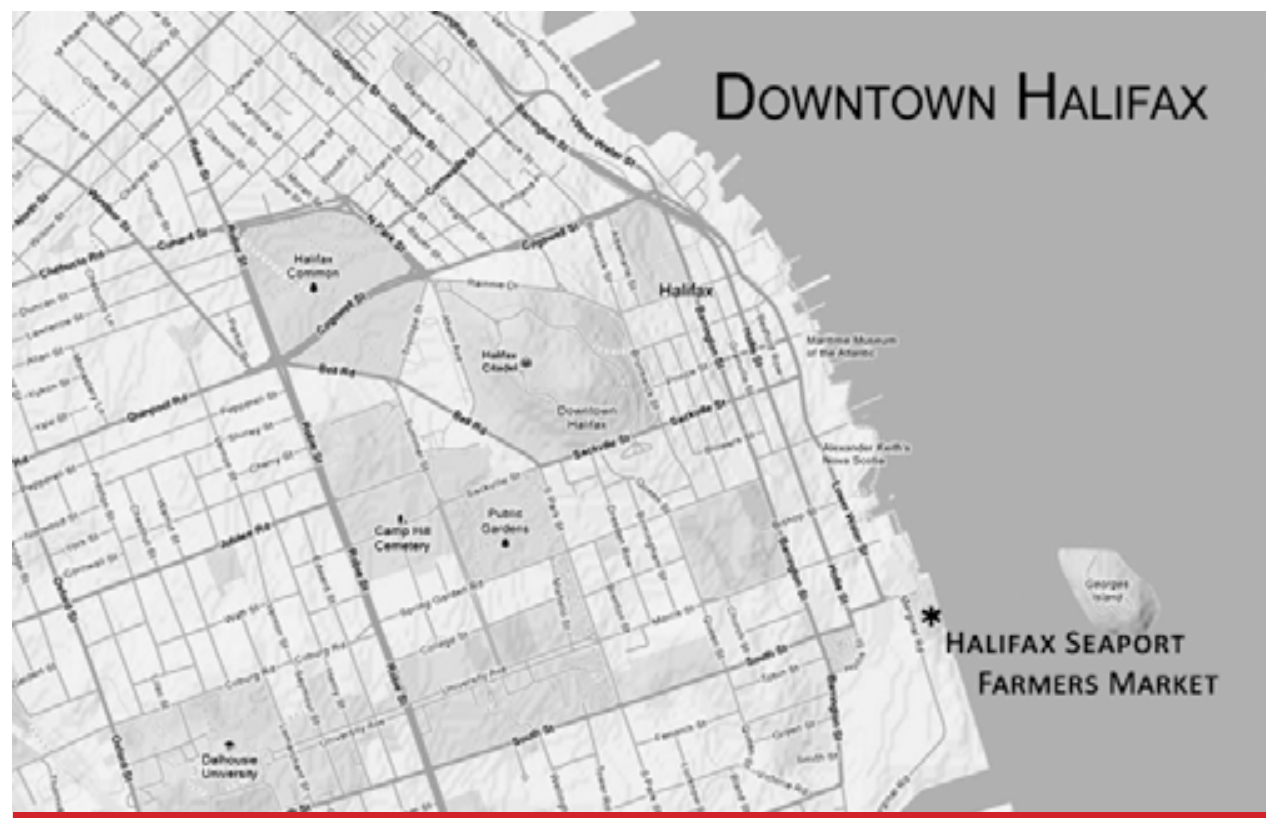

The opening of the International market was co-announced by the Halifax Seaport Farmers' Market and ISIS (Immigration Settlement and Immigration Services) in the fall of 2010. The International market, held at the Seaport Market building on Fridays, marks the confluence of several social trends in both the local city space of Halifax, and the larger Canadian context. ISIS's involvement with the development of the market suggests that there is a substantial benefit to new immigrants through selling the traditional food and crafts of their homelands. Cosmopolitan consumers also presumably benefit from the variety of food and goods up for sale. In this article, I want to ask the question: Who is the International Market for? Obviously the market could have value for both parties, but do these values intersect?

\section{SETTING THE SCENE: HALIFAX AND CANADIAN MULTICULTURALISM}

Halifax is a regional hub city for the Atlantic provinces of Canada. It is a small city, famous for its friendliness towards tourists and folksy traditions while maintaining a measure of urban cosmopolitanism, due to in large part to its five universities, which attract students and professors from elsewhere. The Halifax Farmers Market is a much loved Haligonian institution and is the oldest continuously running Farmers Market in North America, established a year after the founding of the city of Halifax in 1750. Throughout the years, the location of the market has changed several times, and since the early 1980s had been run as a weekly market by a co-operative of vendors in a charming, but very cramped historic brewery building in the center of the downtown district. A revived interest in local food in the last few years encouraged the market's board of directors to expand to a new building of their own in 2010 on the seaport waterfront, close to downtown and 
next to the busy cruise ship terminal. The new Seaport Market building boasts an innovative environmentally-friendly design and has ambitions to open every day of the week. A small group of vendors have been maintaining the older Brewery market on Saturdays, and is holding its own for the time being.

Halifax is not particularly known for its cultural diversity, but its small immigrant population is growing; the number of immigrants coming to Halifax rose by about 1.52 times (from 1700 to 2,585) between 2001 and 2006 (Citizenship and Immigration 2006). Immigrants have also raised the percentage of visible minorities in Halifax from 7\% of the population in 2001 to $7.5 \%$ in 2006 (Statistics Canada 2008). In the last decade, a great deal of attention has been paid by all levels of government to developing programs in Halifax that facilitate the integration of these newcomers into Canadian society to ensure that they find a lasting home here. Most newcomers to Canada choose to settle in the nation's three largest cities, Toronto, Vancouver, and Montreal, where there are already large and well-established ethno-cultural groups. Attracting and retaining immigrants to Atlantic Canada demands innovative strategies that will require the active participation of the established citizenry to create welcoming spaces. Like most Canadians, Haligonians are quite positive toward immigration and are supportive of federal multicultural policies. According to a series of "Focus Canada" polls conducted by Environics, 85\% of Canadians agreed that multiculturalism was important to the Canadian identity in 2003. (Kymlicka 2010, 7).

\section{PRACTICES OF COSMOPOLITANISM ANDTHE SOCIAL SPACE OF MARKETS}

In principle, the International Market serves as a kind of meeting place for different experiences, values and motivations: the experience of the city consumer who is attracted to the international aspect of the market, the experience of the immigrant vendor building a business selling her own homeland food in a public space, and the experience of all actors in the market as a uniquely public retail space. In this section, I examine some of the key concepts in the scholarly literature that help problematize these themes. Since few articles speak to all three dimensions, I deal with scholarship on cosmopolitan patterns of consumption, social geography of markets, and the urban food economy in turn.

Much of the recent scholarly work on ethnocultural food focuses on colonial patterns of consumption by a dominant group in an effort to build a 'cosmopolitan' identity. David Bell describes what he sees as the modern city consumer's 'cultural omnivorousness': the compulsion to eat everything, to be open to everything, to chow down on it all, in the hope that the 'best bits' can then be assembled into a new you - or, rather, a better, more accurate reflection of the real you. $(2004,47)$. In Bell's view, the cosmopolitan consumer is insatiable and self-obsessed, and has no real connection to the producers of the food he or she consumes. Lisa Heldke (2009) also explores the ideas of cultural food colonialism, but is careful to analyze and deconstruct her own history of food imperialism. She recognizes that her standards for authenticity in ethnocultural foods are based on what is most foreign to her own palate, and therefore mastery of recognizing, eating and cooking these foods signifies that she has transcended her own ordinariness. To overcome culinary colonialism is to engage with cooks and eaters from cultures other than our own 'not as resources but as conversation partners' (Heldke 2001, 191).

Ghassan Hage explores the barriers against these conversations in the very influential essay, "At Home in the Entrails of the West: Multiculturalism, Ethnic Food and Migrant Home-building" (1997). Hage accepts that while positive interaction initiated by food sharing is possible, there are often issues of power and subtle racism underlying these casual interactions. He also notices that in the fashionable ethnic restaurants of Sydney's inner city suburbs, there is a greater trend toward 'multiculturalism without migrants' and to describe this trend coins the term 'cosmo-multiculturalism', which depends on consuming the very differences of food to attain value, similar to Bell's vision of cultural omnivorousness. Hage's essay lays out two simultaneous visions of multiculturalism in the same city and acknowledges that a variety of experiences are possible and that geographic location is central to the outcome of interaction. Jean Duruz has also written extensively about intercultural interactions in public and private spaces, and believes that meanings attached to particular foods and practices are complex and shifting $(2000,297)$. Moreover, in a multicultural country, there isn't always a clearly dominant ethnicity; new immigrants and established citizens both participate in 'identity grazing' through food consumption and preparation, which negates the presumed power relations of culinary imperialism $(2000,299)$.

So what does the research say when this interaction happens in a farmers' market instead of a restaurant? The social geography of markets, particularly farmer's markets, has been studied especially as they pertain to city life. A study of British markets by Sophie Watson and David Studdert suggest 
that the ambiguous public/private space of the market can offer possibilities 'for people to mingle with each other and become accustomed to each others' differences in a public space' (2006, 3). Kristin Lowitt has written specifically about Nova Scotia markets, including the Halifax Farmers' Market, and concluded that a sense of community was central to the market experience for both producers and consumers (2009). In a larger Canadian context, Bochra Manai considers the functions of public spaces and places in the integration of immigrants and in building welcoming communities, and has written that markets are public spaces that can 'lead to meetings, furtive or superficial as they may be, that allow for interactions to take place' and that the concept of gastronomy 'brings about opportunities for sociality in intercultural and interethnic relations' (2009, 2). These scholars suggest that there are unique intercultural possibilities for both settled Canadians and newer immigrants within a traditional market environment, but they still leave us with the question of how the exclusive sale of 'international' goods by immigrants in the retail geography of the Halifax International Market influences the consumer/vendor relationship.

At first glance, the addition of an International market day to a farmers' market where the wares for sale are primarily 'local' is an odd pairing. But recent research on alternative food systems helps account for it. Most Canadian Farmers' Markets have moved to heavily favoring 'local' food, with some defining this as food produced within a 100-mile radius of the market (Potter 2011, 63). The Halifax Seaport Farmers' Market vendor handbook loosens the normal requirements that the majority of vendors must be primary producers on International Market day, and stresses that day vendors can play an important economic, social and business role in the market. However it does state 'that primary producers should and must control the HFM as a prerequisite for maintaining it as a farmers' market oriented to the needs of farmers' (Halifax Farmers Market 2010, 5). Given that the trend in farmers markets seems to be moving toward gastronomic isolationism, is the inclusion of a market day dedicated to 'internationality' counterintuitive?

Betsy Donald suggests that the consumer's perception of 'quality' is the common denominator for an array of ethnic, organic, fair-trade and artisanal products available in the city today. Quality may mean different things to different people, but Donald argues that the common thread among these consumers is that they are looking for something different from what is available from more mainstream producers or retailers' $(2006,1904)$. Lowitt noticed a similar trend towards quality in her study of Nova Scotia farmers' markets and that the '(re)emergence of farmers' markets can be seen as part of a wider 'quality turn', that is, a shift among a growing number of consumers away from industrial food to what they perceive to be higher quality food (2009). As a part of the alternative food network, the Halifax Seaport Market might want to be seen as a destination for quality products, and consider the measured inclusion of non-farmers as natural to this goal.

The three issues of colonialist/cosmopolitan patterns of consumption, markets as sites of sociability and local/ethnic pairings of 'quality' food raise the question of whether food can actually prompt intercultural interaction. Many of the scholars mentioned above are curious about the possibilities for, and the limitations of food-based encounters as providers of intercultural interaction. Heldke, Hage and Duruz describe different methods of appropriate interaction which can aid a cosmopolitan's anti-colonial eating. Manai, Donald and Watson argue that the sociality of the market space can facilitate intercultural interaction and even integration. The next section describes how I set out to investigate these themes in Halifax.

\section{RESEARCH METHODS: CONTACTING PLAYERS AND PARTICIPANTS INTHE INTERNATIONAL MARKET SPACE}

The aims of this research, conducted in the time-limited context of an undergraduate seminar in Canadian Studies, were to explore whether the Halifax International Market, as a retail space and a manufactured public space, creates an environment for community relations that can sidestep colonialist patterns and offer opportunity for interaction and integration within its city, province, and country. It also examined the range of market experiences that are possible from the point of view of both consumers and immigrant vendors. Neither group is homogenous, and each individual brings his or her own culture and background and experiences to the interactions in which they engage. Does each party get something valuable from the social space of the International Market?

My main research method was semi-structured interviews, supplemented by observations of the market. I spoke with three kinds of participants in the creation and performance of the market: (1) selected representatives from both the Halifax Farmers' Market management and ISIS in order to understand the story of the development of the market, and (2) vendors and (3) consumers taking part in the market to see what kinds of interactions take place and what they mean to interviewees. ${ }^{1}$ 
1 The research project was approved by Dalhousie's Department of Sociology and Social Anthropology's ethics review board, which deals with ethics review for undergraduate research.

${ }^{2}$ See Grant, Holme and Pettman for further details of the Halifax Seaport Development of which the market is an integral part. [Grant, Jill L, Robyn Holme and Aaron Pettman (2008) 'Global Theory and Local Practice in Planning in Halifax: The Seaport Redevelopment.

Planning Practice and Research 23(4): 517-32.]
I contacted ISIS and the Halifax Farmers' Market Cooperative via e-mail with an overview of my project and a request for an interview. At ISIS, I reached a business development trainer who had helped another staff member who had worked for several years on the project with training clients in preparation for selling at the market since August 2010. I spoke with the trainer in the ISIS offices on February 24, 2011. I conducted an interview with the market manager for the International Market by telephone on March 3, 2011. Each of these semi-structured interviews, designed to explore their motivations for developing the market and their sense of its progress, lasted about 45 minutes and was recorded as digital audio files.

All of the interviews with vendors and consumers took place on a cold and rainy day, February 25, 2011 at the International Market. After I approached possible participants, I identified myself as a Dalhousie student, gave them a brief overview of my topic, and requested a short interview that they could halt or terminate at any time. If we managed to find a spot to sit down for the interview, I asked permission to record the interview; for the others, I took notes where we stood. These interviews lasted about 45 minutes. No personally identifying information was sought from consumers and I noted the names of the vendors' businesses in my notes only. In this paper, specific vendors will be referred to as V1, V2, V3, etc. and consumers will be referred to as $\mathrm{C} 1, \mathrm{C} 2, \mathrm{C} 3$, etc.

I conducted interviews with eight food vendors. I focused my attention on temporary vendors in the central table area, rather than established vendors who lease storefront space. There were only two table-area food vendors selling on that particular day that I did not get a chance to speak with. The interview questions attempted to discover origin of vendors' business plans with ethnic food, attitudes toward Canadian multiculturalism, and their feelings about the market. I also conducted six interviews with consumer groups of two or three for a total of 13 people. Due to the miserable weather, traffic at the market was very light and it is quite possible that my consumer base might have been very different on a more pleasant day. My interviews with the consumers attempted to discern attitudes toward international food and a sense of their retail motivations.

\section{RESEARCH FINDINGS}

\section{THE GENESIS OFTHE INTERNATIONAL MARKET}

A coherent story of the genesis of the International Market emerged from the interviews conducted on February 24 and March 3, 2011 and all information in this subsection comes from information gathered in these interviews. The management of the Halifax Farmers' Market started thinking about the possibilities for community interactions within the market early in the planning stages for the new Seaport Market building several years ago. ${ }^{2}$ The 'Community Connector' program was created by the Market in 2009 with funding from Service Canada (a federal government agency dealing with work and employment, among other things) to develop liaisons between the market and various agencies and groups. The program focused on four areas: food and health, the market as an arts centre, sustainability and the environment, and culture and immigration. My respondent at the market was hired as the connector for the Cultural component with an initial emphasis on investigating opportunities for farmers and other producers to cater to ethnic communities within Halifax. He explains: 
We had a person go out and meet with different immigrant groups to identify what are the food products the immigrant groups are looking for that aren't being produced in Nova Scotia and could that enhance agriculture production. And while we were doing that, many of the immigrants were interested in selling at the market themselves. So we kept that in mind. And then as we were designing this last spring, the market manager said, could we look at creating an international market where it would be different from the traditional market, because the traditional market says the products have to be from Nova Scotia and produced here and all that stuff. So what we did was, I set it all up for them by saying, ok, you can import a product, or you can make a product here, but it has to be authentic to your country. All right? So that was the way to do it. 2001)

He approached ISIS in addition to other community groups like the YMCA (which also runs immigrant integration programs) in early 2010 to see if they would be interested in developing a market day with their clients. ISIS currently puts on a huge range of workshops and classes each day for their clients that aim to strengthen specific abilities that will aid integration into Canadian society, such as English lessons, computer skills, and Canadian business etiquette (see www. isisns.ca/). Their clients had long been requesting a class on market-based food business development, even though few had any prior experience in the food industry. The ISIS business development department had been working towards securing a venue for businesses selling newcomers' foods for several years, but costs for renting facilities like the Halifax Forum were prohibitive and the existing Brewery Market was small and only open one day a week. By the time the Market management contacted ISIS in 2010, much of the foundation work for the International Market had already been laid by ISIS, and a group of newcomer clients interested in the project had already been identified.
In order to get their clients ready to sell at the market, ISIS staff provided initial business development training, including advice on what to sell, how much variety to sell, and how to price products to ensure they would pay themselves fairly. A business trainer from ISIS described the training process:

so we had 6 information sessions for the clients, telling the clients what the market was all about, what they were going to need, what the market was going to provide them with in terms of materials and infrastructure type things and then we had the food handlers course we had all our clients take the food handlers course.

The Farmers Market 'Community Connector' conducted market-specific training in the ISIS classrooms, including providing connections to government inspected kitchens in the community where food preparations must happen to comply with official safety regulations.

The International Market finally opened on the first Friday of November with around 30 food and craft vendors. All parties involved mentioned that there were logistical things to iron out at the beginning, such as access to water and refrigeration but generally the market was on a good footing by the time of the official opening on November 19. The ISIS business trainer admitted that although there was a lot of initial interest by their clients for the market, the many 'rules and regulations weeded out who was just kicking the can, and who really wanted to sell at the market'. She mentioned that 'we had a lot of issues with the Department of Health turning up - they were at the market, like, continuously.... At the time of the interviews, there were only fourteen food and craft vendors currently selling at the market, half of whom had originally taken the information sessions through ISIS. The market management stated that many of the craft vendors intend to come back when the weather is nicer and the traffic picks up.

The basic problem, traditional of all markets that in January, everything drops. January, February, March. And so, we had it going pretty good right up to Christmas, and then I knew after Christmas it was going to be a real problem. That's the way it is. So hopefully when April rolls around, we'll get more people coming back. 


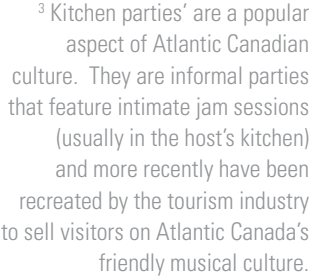

friendly musical culture.
My respondent from the Farmers' Market is full of ideas to increase business and traffic at the market including themed days like International Kitchen Parties where different groups will sing and dance and play over the supper hour. ${ }^{3} \mathrm{He}$ is also committed to the idea of the market as a learning centre for the community, and he is planning theme days that put a spotlight on a specific part of the world that could include lectures by university professors or representatives from NGOs, travel information from travel agents, and fair trade information in addition to the popular food and dance aspects of the cultures.

In many ways the International Market is not so different from the regular market, where vendors who sell ready-to-eat food are classified as secondary producers. The International Market vendors are therefore able to compete for the spaces on the more lucrative Saturday selling day (Halifax Farmers'Market 2010, 1). The difference is that the International Market dedicates space to international vendors and is the only market day that also allows completely non-local and non-food items to be sold in the market building. It is a new departure for this particular market, which has always been focused on locally grown produce, and Nova Scotia artisan made crafts. Betsy Donald's view of the urban creative-food economy where 'quality 'may be defined as the ability to find an 'authentic' product from their homeland that cannot be purchased at a mainstream food retailer. For another consumer it may be about consumer products grown locally; for another it may be about buying products free from pesticides or herbicides, regardless of the source. However, once could argue that the common thread among these consumers is that they are looking for something different from what is available from more mainstream producers or retailers.' (Donald and Blay-Palmer 2006, 1904).

\section{VENDORS' EXPERIENCES OFTHE MARKET SPACE}

As mentioned earlier, February 25, was a cold and rainy day in Halifax, and the weather probably had an impact on the quantity and length of interviews at the market. However, certain patterns still emerged in the vendor and consumer interviews. I begin with the vendors' points of view. To my surprise, given the apparent extent of the ISIS training, only two of the vendors I interviewed had been involved with ISIS. The business facilitator from ISIS had suggested that at least seven of their original clients were still selling at the market, so it is possible that the few vendors I didn't get to interview did go through the ISIS information sessions. It is also possible that some vendors decided to forgo selling at the market on that particular day, due to the poor weather. Other vendors came to the market by different means: one had some contact with YMCA programs and had a prior food franchise business but was now looking to downsize her business commitment, three individuals had also sold at the Brewery or Seaport market before, and the other two vendors were starting new businesses and had applied to the Seaport Farmers' Market directly. Half of these vendors are Canadian citizens, and half hold permanent resident status.

All of the vendors were quite positive about the social aspect of the market and several mentioned that it was the best part about working there. One of the vendors that had been referred by ISIS said this about the social aspect of the market:

Well, that's the best thing for us. Strictly, we're not pushed for money, but we're pushed for social interaction. And this market is a welcome change, really. It's very good. You interact with people, especially Canadian people to buy - at the same time, other people working here, all these vendors. We just feel it's great. (interview,V1). 
${ }^{4}$ This term is used in Nova Scotia to refer to the Black population whose roots in the province go back to the 18th century
Another vendor saw the social aspect as a good selling point to the market and remarked, 'People like to come away from their computer, and interact with people like me. We have regular customers that come and talk.' (V2). All vendors expressed that they had gotten to know other vendors and some also exchange food.

The priority of producing 'homeland food' was less important to newcomer vendors than I had expected, given the planned theme and regulation of the International Market. All of the vendors were proud to talk about the uniqueness of their foods, and some shared cooking tips, but several vendors reminded me of the requirement on International day to sell food from their country of origin and mentioned they like eating a wider variety of foods at home (V1, V2, V4). None of the vendors had any problems finding authentic ingredients in Halifax and stated whatever they couldn't find at Costco or Atlantic Superstore could be supplied at the local ethnic shops. Only two vendors stressed the importance of using locally sourced ingredients, including the only vendor born in Nova Scotia. (V7, V2).

There were varied opinions about the success of Canadian multiculturalism and the feeling of welcome from Canadians. All but one participant thought that multiculturalism was a positive aspect of Canada and that Canadians were (mostly) welcoming to people of different backgrounds. Newcomers tended to elaborate more about the positive experience they had had with Canadians than immigrants who had been here for some time. One newcomer vendor was already contributing to the community by volunteering at ISIS as a coordinator for diversity workshops and was enthusiastic about sharing knowledge of his home country - during his interview, he showed me a map of his country to explain a bit of its geography as it related to different kinds of foods (V1). The only negative response to my questions about the welcome given by Canadians was from the African Nova-Scotian ${ }^{4}$ vendor who said that there was only token acceptance by Canadians toward people of different backgrounds and that Halifax was not changing in its views toward minorities (V7).

All of the vendors were somewhat disappointed with the level of business at the International Market and some mentioned that they were just breaking even (V1). They were generally positive that business would pick up once the weather was better. One vendor had extensive ideas about what was needed at the market:

That's what I found, they (consumers) want to have their food and they want to spend some time here. So we're visualizing that we want to work on that, how they can spend more time here, either for the children, or there can be some cultural program, some buskers program... The second thing, we were talking among ourselves, another thing is, let this market become more friendly, more hospitable? Otherwise people buying certain things, they would prefer to go to a mall, instead of coming here. So we have to create something different, something special (V3). .

This vendor was also careful to stress that in summer, he didn't want to cater to cruise ship customers (who arrive on ships at the Seaport) at the expense of his regular customers. He doubted that the food vendors would benefit too much from this type of tourist anyway, since they can't take food back with them on the boat, where all the food they want is included in their cruise anyway. I found it noteworthy that this vendor had been in Canada the least amount of time compared to the other vendors, but was the most excited about welcoming 'regular Canadians' to his market. 


\section{CONSUMERS' EXPERIENCES OFTHE MARKET}

All of the 13 consumers interviewed were Canadian citizens and six described their ethnicity as Canadian as well (several further identified as Quebecois or Newfoundlander). Nine consumers mentioned that they had originally lived in another Canadian province and two consumers were tourists from another Canadian province. By my observation, ten of the consumers were in the 18-35 age range and three were over 50. Three consumers had at least one parent who had not been born in Canada. All of the consumers I spoke with were white, and appeared middle class, although no specific questions were asked about income. I tried not to disrupt anybody's lunch, and approached small groups of people as they were on their way into the market, or who had just finished eating.

Most consumers I interviewed at the International market were generally interested in culture and were somewhat regular visitors to the regular Farmers' Market on Saturday. Only two groups of consumers included people who had been to the International market before this particular day. All of the consumers expressed concern for quality and were generally convinced of the inherent high quality of local food; six consumers made a regular effort to buy organic produce. Only the tourists, who were visiting Halifax for the Canada Winter Games, were generally uninterested in organic and ethnic food, although they did say that they enjoyed going to the Mennonite markets in Kitchener once or twice a summer for the fresh, high quality food (C8 and C9). All consumers appreciated the direct contact with the food producer and saw it as an important aspect of their desire to purchase food at the market. Several customers were aware of Fair-Trade food and tried to support it, if not actively seek it out (C6, C7, C11, C12, C13). One consumer who was an International Development student at Dalhousie University said that purchasing local and fair-trade food was emphasized so often at school that she sometimes bought it out of guilt (C13).

Most of the consumers I spoke with were quite positive about the availability of ethnic food in Halifax but some individuals wanted to see even more choice. One consumer who had grown up in Ottawa said, 'Coming here - I don't think it was such a shock but when you talk about - Let's get take out Indian... Well, IS there take-out Indian in Halifax?' His partner, who was originally from a small town in Northern Manitoba countered, 'It's different for me, where I come from it's the opposite. Here there's so much food to try!' (C1 and C2). Almost all of the consumers were very satisfied by the level of authenticity of ethnic food at the market.

Interestingly, several consumers had a very savvy reaction to the word authentic; one had done a lot of cooking while travelling in different parts of the world and mentioned that authenticity can change according to where you are (C6), and another used air quotes when saying he had no idea what 'authentic' meant and declined to act as an authority for something he didn't know much about (C2). Only one consumer, a self-declared food snob, had low opinions of the authenticity of the food at the market and suggested that some of the food the vendors were selling had come from a frozen box. He also described Halifax as a 'backwater shit-hole' when it came to finding ingredients for his Mexican, Indian, and Thai recipes (C10). This consumer was the only individual I encountered during this project that reflected the type of voracious food colonialism described by Bell (2004) and Heldke (2003); the majority of consumers seemed to have less preconceived notions of what authenticity entailed.

\section{DISCUSSION:TRANSCENDING COSMO-MULTICULTURALISIM?}

It is clear that the Halifax Seaport Market Management is attempting to create a space that will be important to the community as a place to gather together to learn about each other and the environment we all share through the further development of the International Market. Their plans for putting on educational programming relating to different parts of the world might push the market's interpersonal scope further than the 'saris, samosas and steel bands' popularization of multiculturalism, which is often the most immediately accessible way of introducing new cultures to what is perceived as a homogenous mainstream public. It is also clear that the international vendors themselves are very invested (financially and socially) in the market and it appears that there is some collaboration with management to see how their input could help the economic success of the market. Peter Li has written that integration is about incorporating newcomers into a democratic process of participation and negotiation that shapes the future' (2003, 330), and it appears that the International market does provide some opportunities to do just that.

The market also benefits from the International Market by simply introducing new customers to their retail space. By 
offering a combination of local, fair trade, and international goods at the market, and looking to widen the scope of the International market by adding free entertainment and valueadded lectures, the International market also achieves three out of the four attributes necessary for a vibrant public market space as described by Watson and Studdert (2006,viii): features to attract visitors to the site, opportunities to linger, and an active and engaged community of traders. (The fourth attribute for success is having good transit service to the market, which could be researched further for its impact on inclusion opportunities.) The market management admitted that the new market building provided an immense amount of space to house new vendors and that they needed to find new producers to fill up the market on a daily basis. The question of how to get new customers and new producers was a main factor in the creation of the Community Connectors program in the first place when planning the new market space. The market's management stated that focussing on community and inclusion just makes good business sense.

The consumers at the International Market on February 25, 2011 appeared at first to be a homogenous, white, middle class group, but upon closer inspection were perceived to encompass a range of income levels, cultural backgrounds, and attitudes toward international food. I got a sense from all of the consumers that they were very careful where they decided to spend their money and that for some, the higher costs for organic, local or fair-trade foods were justified by a personal set of ethics and a desire for quality that went hand in hand, and didn't necessarily mark them as the urban elite. This echoes Betsy Donald's vision of the urban creative food economy, even though the International Market is a tiny microcosm of the food systems in large cities like Toronto.

The attitudes of the consumers started to diverge when talking about ethnocultural foods. Most of the consumers I interviewed were originally from other provinces in Canada and many had travelled extensively. In some cases, the International market provided the cosmopolitan range of foods they were accustomed to at home (C2, C10, C11). Some consumers considered themselves foodies and clearly enjoyed the variety of foods laid out for consumption (C3, C6, C11, C12). One of the consumers described her love of ethnocultural foods; 'We kind of move around the world, don't we?' (C3). Hage might consider these attitudes cosmo-multiculturalism (especially the self proclaimed 'food snob' consumer), but most of these consumers spoke in a tone of respect and friendly admiration. Some of these same consumers were extremely self-reflexive in the way that they talked about food (C2, C6, C11) and appeared to have negotiated for themselves very anti-colonialist ways of perceiving food in the way they refused to act as authorities about the ethnocultural food they sought out and enjoyed. Ian Cook suggests that in a multicultural country,

There is no automatic, powerful, taken-for-granted, Othereating white personality that needs to be dismantled and reconstructed. It's already fragile and bitty because people's heterogeneous biographies and everyday lives are often both food colonialist and anti-colonialist.... Few mainstreamers have, for instance, lived in the same place their whole lives. They've crossed culinary cultural borders in their life histories. (Cook 2008:828)

As one of the vendors mentioned to me after I shared that my father had been a refugee to Canada, 'Well, everybody's dad was a refugee to Canada. (Laughs) Except for the First Nations!' (V1). This recognition of his own status as essentially the same as long-term Canadians may give us a model of interaction where we can begin to consider ourselves as 'Others' within a multicultural framework in order to meet others on an equal footing

\section{CONCLUSION: THE VALUE OF WELCOMING SPACES}

To answer my original research question, Who is the International Market for?, the International Market appears to have value particularly for newcomer business owners who sell at the market, educated urban consumers, and the Market management itself. It was difficult to gauge the amount of intercultural interaction actually occurring between vendors and consumers at the market from my limited interviews. Certainly, there was a lot of respect on the behalf of consumers toward the vendors and vendors said that most Canadians were very interested, accepting, welcoming and fair (V1,V2,V3,V6). In light of research describing restaurant consumption of ethnocultural food (Hage 1997; Bell 2004; Heldke 2001), it seems that this respect is more difficult to foster outside of this market environment, where there is at least a certain level of 
direct interaction with the producers of food. The social retail space of the International market appears to attract consumers who are already willing to move beyond the self-obsessed and insatiable cosmopolitan consumerism described by Bell (2004) to an awareness of the people and cultures producing the food.

On a larger scale, the entrepreneurship programs provided by ISIS are very powerful integrative tools that empower newcomers to quickly become invested in the community. Selling at the International market is both a low-risk business and also a community integration strategy that, as Peter Li (2003) suggests, allows newcomers to participate in a very social aspect of Canadian life in Halifax. The market is, of course, just one very small aspect of the larger issue of integration and social inclusion. According to Statistics Canada, the Atlantic region is one of the most ethnically homogenous places in Canada, with a lower rate of visible minorities than other regions (Statistics Canada 2008). Immigration is vital to grow or even maintain the population base in Halifax and Nova Scotia and successful integration of new immigrants is vital to help them stay here. Halifax has a lot at stake in the creation of welcoming spaces, and it appears as though the community is making an effort at making this happen. 


\section{WORKS CITED}

Bell, David. 2004. 'Taste and Space: Eating out in the city today." In Culinary Taste: Consumer Behaviour in the International Restaurant Sector, edited by D. Sloan (Ed), 43-57. Oxford: Elsevier Butterworth-Heinemann.

Citizenship and Immigration Canada. 2006. Socioeconomic Profiles of Immigrants in the Four Atlantic Provinces — Phase II: Focus on Vibrant Communities. Accessed January 22, 2012. http://www.cic.gc.ca/english/resources/research/socioeconomic/section2.asp

Cook, Ian. 2008. “Geographies of Food: Mixing." Progress in Human Geography. 32 (6), 821-833.

Donald, Betsy., \& Alison Blay-Palmer. 2006. “The Urban Creative-Food Economy: Producing Food for the Urban Elite or Social Inclusion Opportunity?" Environment and Planning A, 38(10), 19011920.

Duruz, Jean. 2000. "A Nice Baked Dinner...or Two Roast Ducks from Chinatown?: Identity grazing." Continuum 14.3:289.

Hage, Ghassan. 1997. "At Home in the Entrails of the West: Multiculturalism, Ethnic Food and Migrant Home-Building." In H. Grace, G. Hage, L. Johnson, J. Langsworth \& M. Symonds (Eds.), Home/World: Space, Community and Marginality in Sydney's West, 99-153. Annandale, NSW: Pluto Press.

Heldke, Lisa. 2001. "Let's Cook Thai: Recipes for Colonialism." In S. Inness (Ed.) Pilaf, Pozole, and Pad Thai: American women and Ethnic Food. 175-198. Amherst: University of Massachusetts Press. 2003. Exotic Appetites. New York: Routledge

Immigration Settlement \& Integration Services. 2010. Halifax Seaport International Market. Accessed January 23, 2011 at http://www.isisns.ca/news/halifax-seaport-internationalmarket/.

Kymlicka, Will. 2010. The Current State of Multiculturalism in Canada and Research Themes on Canadian Multiculturalism,2008-2010. Department of Citizenship and Immigration Canada. Accessed November 16, 2011 at http://www.cic.gc.ca/english/pdf/pub/multi-state.pdf.

Li, Peter. 2003. “Deconstructing Canada's Discourse of Immigrant Integration." Journal of International Migration and Integration, 4 (3), 315-333.

Lowitt, Kristen. 2009. “Exploring Connections Between People, Places and Food in Three Nova Scotia Farmers' Markets." Cuizine, 2 (1). Accessed March 3, 2011. http://id.erudit.org/ iderudit/039514arz 
Manai, Bochra. 2009. Importance of Public Space in the Integration Process and in Building Welcoming Communities. Accessed January 23, 2011 at http://canada.metropolis.net/pdfs/ manai_e.pdf.

Potter, Andrew. 2011. “Thinking Local, Acting Loco?" Maclean's Magazine. January 17. p.63-64.

Statistics Canada. 2008. Canada's Ethnocultural Mosaic, 2006 Census. Accessed March 22, 2011 at http://www12.statcan.ca/english/census06/analysis/ethnicorigin/pdf/97-562-XIE2006001.pdf.

Halifax Seaport Farmers Market. 2010. Vendor Handbook. Accessed February 25, 2011 at http:// www.managemymarket.com/Uploads/OrgFiles/149/ Seaport\%20 Vendor\%20Handbook.pdf

Watson, Sophie and David Studdert. 2006. Markets as sites for Social Interaction: Spaces of Diversity. Bristol: The Policy Press.

This work is licensed under a Creative Commons AttributionNonCommercialNoDerivs 3.0 Unported License. 